\title{
THE ROLE OF THE NERVOUS SYSTEM IN THE MAINTENANCE OF VENOUS HYPERTENSION IN HEART FAILURE
}

\author{
BY \\ D. HALMÁGYI, B. FELKAI, J. IVÁNYI AND G. HETÉNYI JR. \\ From the I Department of Medicine and Department of Physiology, University Medical School, Szeged, Hungary
}

Received June 7, 1951

The mechanism of venous pressure elevation in chronic congestive heart failure is not yet well understood. Data collected in the last decade failed to substantiate the "backward failure " theory of high venous pressure. It was demonstrated that "high output failure" results in phlebohypertension as well as the "low output" form of the disease (McMichael, 1948). On the other hand, no increment in venous pressure occurs following severe damage (Starr et al., 1943; Bakos, 1950) or temporary exclusion (Rodbard and Wagner, 1949) of the right ventricle, or after elevating venous resistance (Guyton, 1950) in the dog.

According to the "forward failure" theory (Warren and Stead, 1944), venous hypertension is caused by an increase in circulating blood volume in consequence of defective renal excretion of sodium. Venous pressure elevation produced by raising blood volume with enormous amounts of infusion fluids in dogs proved, however, to be only transient (Yeomans et al., 1943; Gowdey et al., 1950; Huckabee et al., 1950). The high blood volume in erythræmia, and the sodium retention in chronic nephritis does not lead to venous hypertension (Landis et al., 1946). The accumulation of œdema fluid does not always precede venous hypertension (Gibbons, 1948). High blood volume, as recently stated by Ross et al. (1950) does not seem to be a constant symptom of chronic heart failure.

The chief limitations of these hypotheses consist in the rigidly mechanistic view in which they explain the process of venous pressure elevation. Chronic congestive heart failure is the result of an inbalance between an increased demand (Hamburger and Lev, 1925) and a decreased supply of oxygen. In response to the resulting hypoxia, adaptive changes occur in tissue metabolism (Shorr et al., 1951), in the adrenal cortex (Halmágyi et al., in press), and in the circulation, the latter being mainly governed by the nervous system. Nervous regulation of hypoxia-induced circulatory changes is in good accord with the well known vulnerability of the brain towards lack of oxygen. The nervous system also influences the veins (reviewed by Gollwitzer-Meyer, 1932; and-McDowall, 1935). The close correlation between changes of arteriolar and venous tone bespeaks a simultaneous spread of vasomotor impulses to arterioles and veins. In heart failure, however, an independent elevation of venous pressure occurs. Investigating the contribution of the venomotor tone in maintaining venous hypertension, two questions arose (Landis and Hortenstine, 1950):

Does the general contraction of the veins elevate their pressure?

Do the veins react as an independent part of the vascular system?

Most authors answer these questions in the negative (Landis and Hortenstine, 1950; FremontSmith, 1949; and others). Nevertheless, some isolated observations seemed to support these assumptions. Scaffidi et al. (1940), Delius et al. (1948), and Hammerschmidt et al. (1950) report a rise in venous pressure following administration of ergotamine derivatives. Paredrinol raises venous pressure by effecting a constriction of the veins (Iglauer et al., 1940). Injection of tetra- 
ethylammonium-bromide (TEAB) is followed by a sharp decline in previously elevated venous pressure (Hayward, 1948; Relman et al., 1949; Schuman, 1950). Methonium compounds have a similar effect, as reported by Turner (1950). Sodium nitrite results in dilatation of the venules, as evidenced by Weiss et al. (1937) and Willkins et al. $(1937,1938)$. All these data refer to peripheral venous pressure, without simultaneously determining other circulatory factors.

The following experiments represent an attempt to re-evaluate and extend the available data with the aid of modern clinical methods not being in use at the time of earlier studies.

\section{MethodS AND MATERIAL}

Investigations were carried out on 84 men and women, in the early morning hours, at least eight hours after the intake of the last meal. Sixty-two of them suffered from chronic congestive heart failure of various origin. None of them received any treatment or sedative prior to the experiments.

In about half of the cases cardiac catheterization was performed, as described by Cournand and Ranges (1941). The tip of the catheter was placed in the right atrium under X-ray control, through a needle inserted in the antecubital vein. A permanent cannula was inserted in the femoral artery too. Pain was prevented by novocaine anæsthesia. Oxygen consumption was measured by using a standard basal-metabolism equipment (system Knipping); arterial and venous blood samples were simultaneously withdrawn. The patient was placed during the whole procedure on a specially fitted X-ray table, providing relative comfort. Observations were started 30 minutes following the insertion of the catheter and the arterial cannula, at a time when pulse rate and pressures were stabilized on a resting level.

The determination of cardiac output was based on the Fick principle, and was calculated on one square meter body surface area (cardiac index). Arterio-venous oxygen difference was determined photoelectrically (Issekutz et al., 1949).

Right atrial and femoral arterial pressures were measured with a Sanborn electromanometer (Rappaport and Sarnoff, 1949) which recorded on an Elmquist cardiograph. Mean pressures were obtained by electric integration. Peripheral venous pressure was measured with a saline manometer in the antecubital vein. The zero point for all measurements was $10 \mathrm{~cm}$. anterior to the back, with the patient recumbent.

If not stated otherwise, substances were administered by a slow intracardiac or intravenous infusion by means of an electric pressure pump. Prior to and following all procedures, cardiac output and pressures were repeatedly determined. Each individual value represented the average of at least two separate determinations, not deviating more than 5 per cent.

Dihydroergotamine (DHE-Sandoz), 1. mg.; hydergin (Sandoz), a mixture of DH-ergokryptine, DH-ergocornine, and DH-ergokrystine, $0.3 \mathrm{mg}$.; and sodium nitrite, 0.04-0.06 g. were administered to study the influence of substances effecting the smooth muscle of the vascular system. Pulsoton (chinoin) (m.-oxyphenyl-isopropyl-amine), 0.005-0.01 g. was given investigating the effect of a sympathomimetic agent on venous pressure.

TEAB (4-6 mg./kg. body weight), atropine sulphate (Merck, $1 \mathrm{mg}$.), and N,N-dibenzyl- $\beta$ chloroæthylamine- $\mathrm{HCl}$ (dibenamine, $3-5 \mathrm{mg}$. $/ \mathrm{kg}$. body weight) were given to establish the effect of ganglionic, sympathetic, and parasympathetic blocking on venous pressure. The dibenamine infusion lasted 40-50 minutes, and was preceded by barbiturate sedation to avoid untoward central excitation (Nickerson and Goodman, 1948).

The role of the central nervous system in maintaining venous hypertension was studied during sleep. Sleep was induced by administering sodium amytal $(0 \cdot 20-0 \cdot 40 \mathrm{~g}$.$) , orally; in other cases$ evipan sodium ( $0.50-0.75 \mathrm{~g}$.), intramuscularly; or chloralhydrate $(1.5 \mathrm{~g}$.$) , rectally. In one instance$ the patient spontaneously fell asleep. Criteria of optimal sleep were as follows: $(a)$ the absence of initial excitation, $(b)$ quietness and depth of sleep, $(c)$ normal respiration, $(d)$ the possibility of waking the patient at any time with any simple stimulus. Experiments not conforming to these 
requirements were disregarded. In three cases administration of $0.75 \mathrm{~g}$. evipan sodium failed to induce sleep. In a single case $0.50 \mathrm{~g}$. evipan sodium was followed by deep coma necessitating the administration of picrotoxine. These cases served as control observations regarding the effect of insufficient or toxic doses of barbiturate.

Another series of experiments were carried out on male and female, unanæsthetized animals: 7 dogs $(8-15 \mathrm{~kg}$.), and 4 cats $(2-3 \mathrm{~kg}$.). Arterial pressure was measured in the right femoral artery using a mercury manometer, and venous pressure was measured in the left femoral vein by means of a saline manometer. Reference level was a point $5 \mathrm{~cm}$. above the surface of the table. The animals received intravenously $0 \cdot 1-1.0 \mathrm{mg} . / \mathrm{kg}$. body weight of ergotamine (gynergen-Sandoz), or DHE. Four dogs were subjected to intravenous saline infusions. The priming rate of the infusion was $17 \mathrm{ml} . / \mathrm{min}$. $\mathrm{kg}$. body weight. This was followed by a sustaining rate of $1-3 \mathrm{ml} / \mathrm{min} . / \mathrm{kg}$. body weight. Pressures were continuously determined. At the maximum level of the venous pressure increase TEAB was given in a dose of $5-10 \mathrm{mg} . / \mathrm{kg}$. body weight, intravenously.

Owing to the many groups of individual experiments, a form of tabulation was devised promising an easy survey of the results. The figures of Table I represent mean values of the individual experiments. The statistical significance of the differences was calculated by the " table of " $t$ " " (Fisher, 1934).

\section{RESULTS}

Effect of Ergotamine Derivatives. Circulatory changes following the administration of DHE are shown in Group I of Table I. A significant increase in peripheral and central venous pressure occurred. No significant change was observed in arterial pressure and cardiac output. The rise in venous pressure preceded the onset of bradycardia (Fig. 1). Simultaneous pressure measurement in the antecubital vein and right atrium following DHE administration indicated an increase in the venous pressure gradient (Fig. 2). The venous pressure elevation lasted several hours. No difference could be demonstrated in the effect of DHE on normal persons and on patients in heart failure.

The effect of previously administered atropine on venous pressure elevation following DHE

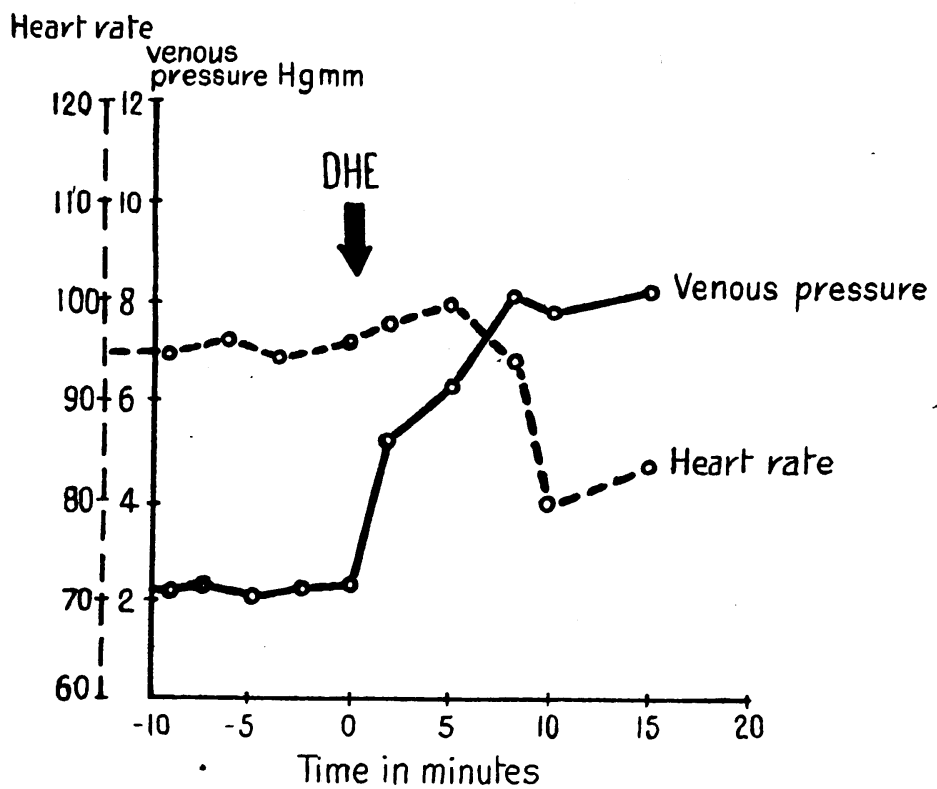

FIG. 1.-Time relation of two characteristic effects of DHE: venous hypertension and bradycardia. 


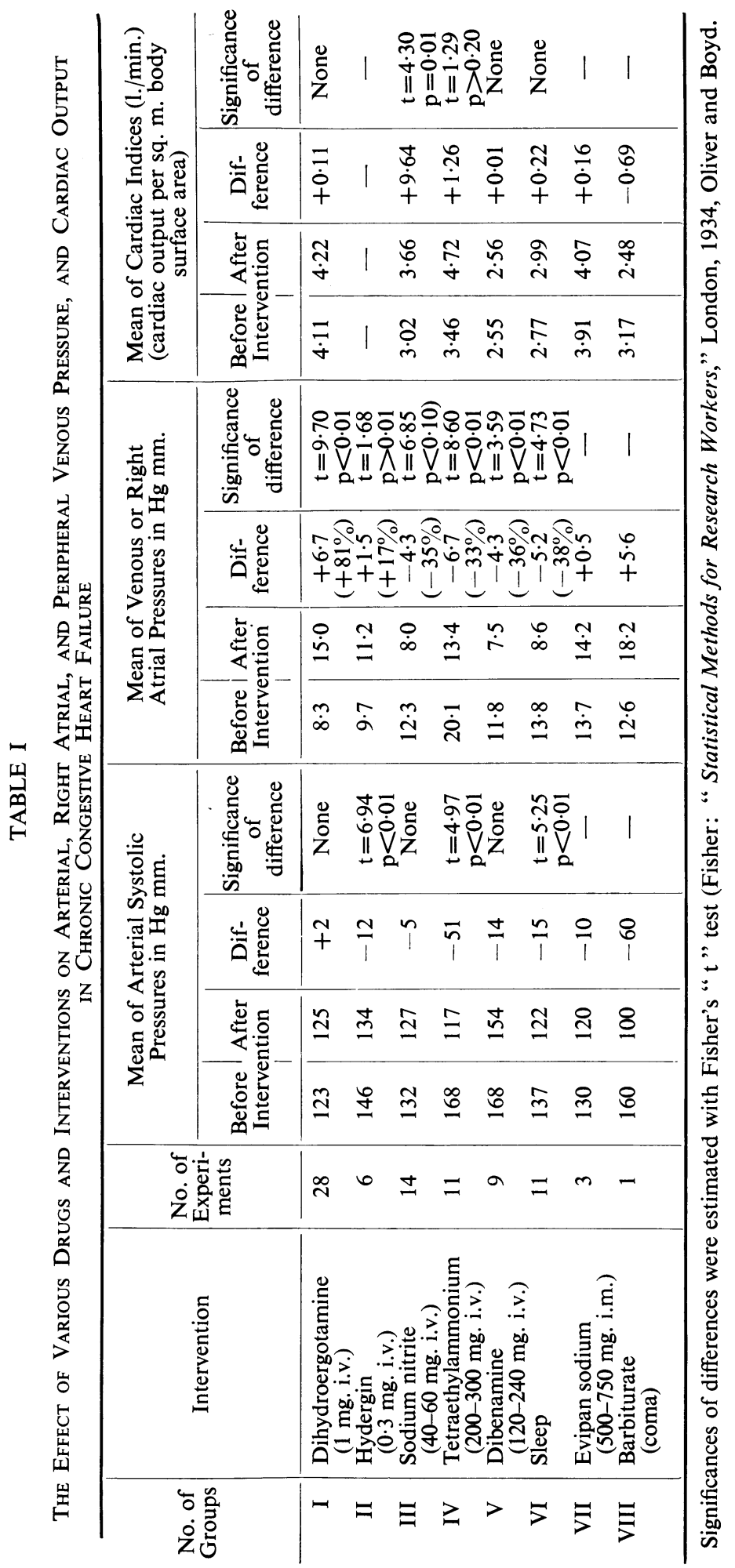




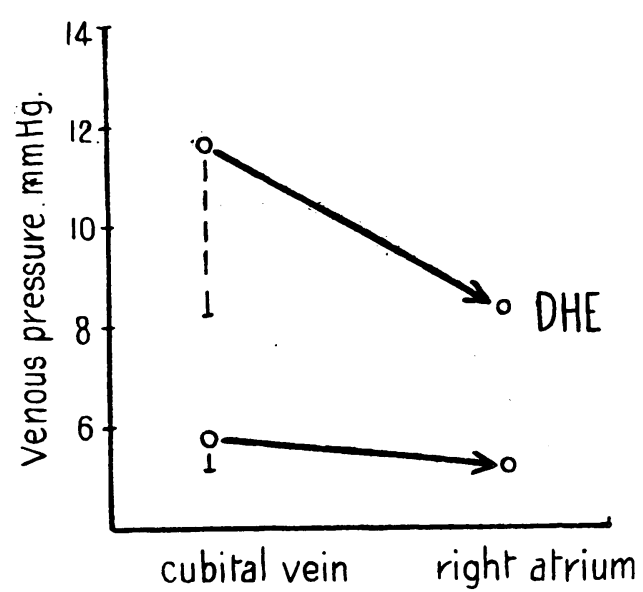

Fig. 2.-Change in the venous pressure gradient following administration of DHE.

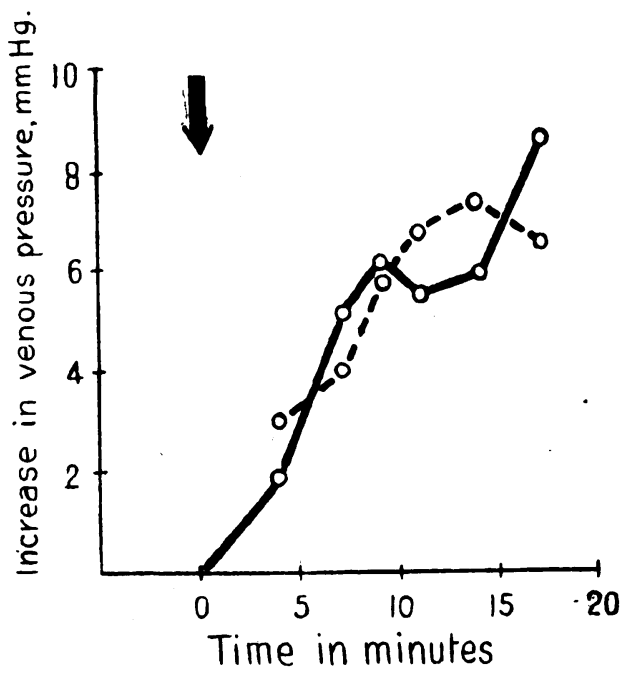

- $\rightarrow-\infty$ DHE + atropine

FIG. 3.-The effect of previous atropine intake on DHE induced venous hypertension.

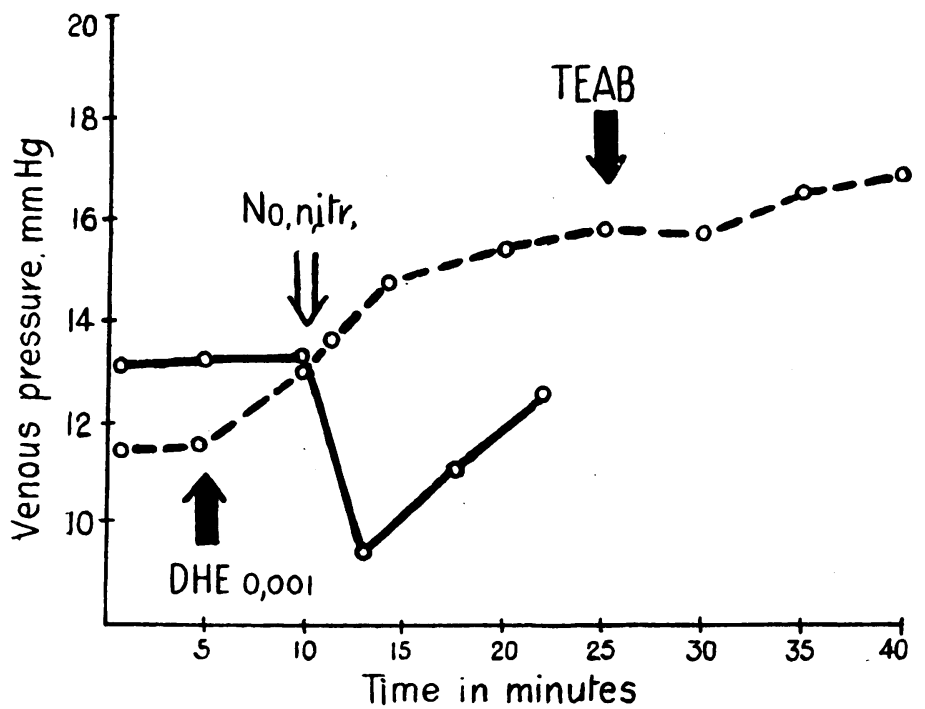

FIG. 4.-The effect of TEAB and of sodium nitrite on DHE induced venous hypertension.

intake was studied. The effect of DHE on venous pressure was established on six normal and cardiac patients. The next day the experiment was repeated after having previously administered atropine. The onset of the effect of atropine was controlled on the pulse rate and pupils. Fig. 3 illustrates the average values. Atropine does not seem to influence the effect of DHE on venous pressure, nor does it influence venous hypertension when administered following DHE intake.

Venous pressure elevation brought about by DHE was not influenced by TEAB, but dropped promptly to almost normal levels after administration of sodium nitrite (Fig. 4).

Hydergin resulted in a less pronounced increase of venous pressure (Group II of Table I). 
Ergotamine and DHE did not influence the venous pressure in three dogs and four cats.

Pulsoton was given to three persons and pressures on the venous and arterial sides of the circulation were registered. Pressure increased on both sides. Administration of DHE resulted in a further increase in venous pressure, arterial pressure remaining unaltered (Fig. 5).

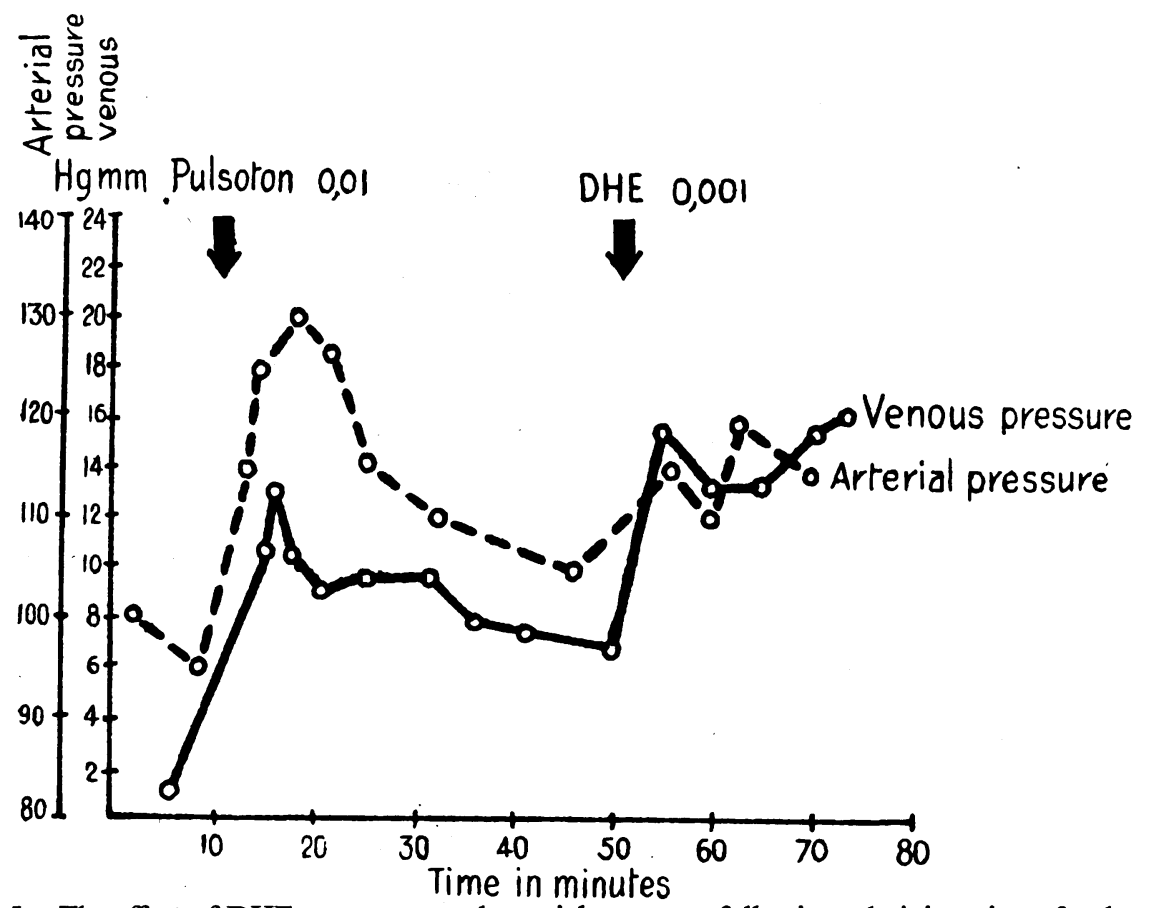

FIG. 5.-The effect of DHE on venous and arterial pressures following administration of pulsoton.

Effect of Sodium Nitrite. Circulatory changes following administration of sodium nitrite in congestive heart failure are demonstrated in Group III of Table I. A marked decrease in right atrial pressure and an increase in cardiac output occurred. Arterial pressure remained practically unchanged. Calculating the correlation between the changes in venous pressure and cardiac output, the most probable regression coefficient was found to be $12 \cdot 0$, with a standard error of 17·1. A causal connection between increase in cardiac output and in decrease in right atrial pressure seems therefore unlikely. Sodium nitrite had no effect on normal venous pressure.

Effect of TEAB. Circulatory changes following the administration of TEAB in congestive heart failure are demonstrated in Group IV of Table I. TEAB resulted in a marked drop in right atrial and arterial pressures, with a simultaneous (but hardly significant) increase in cardiac output. No effect was observed on normal venous pressure.

The elevated venous pressure in dogs subjected to large, rapid, intravenous infusion, remained unaltered following administration of TEAB (Fig. 6).

Effect of Dibenamine. Circulatory changes following administration of dibenamine in congestive heart failure are demonstrated in Group V of Table I. Dibenamine resulted in a marked decrease of right atrial pressure. Cardiac output remained unaltered. The decrease of venous pressure preceded all other well known effects of the drug, as arterial hypotension, mydriasis, and coryza (Fig. 7). These were only observed some hours after the experiment had been completed. No effect was observed on normal venous pressure.

Effect of Sleep. Hæmodynamics of sleep in congestive heart failure are demonstrated in Group VI of Table I. Besides a decrease in arterial pressure a marked decrease in right atrial 


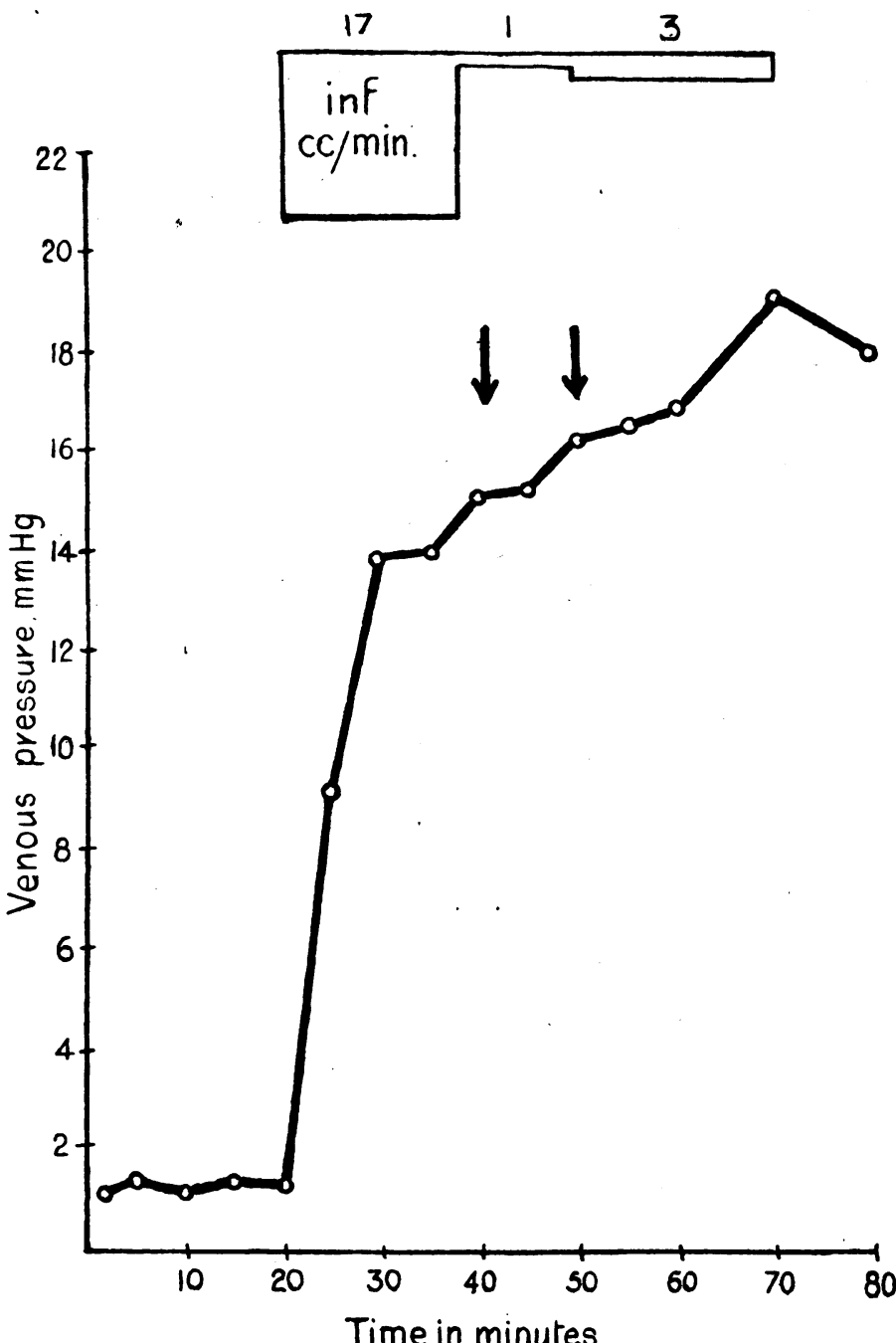

FIG. 6.-The effect of TEAB on the mechanically elevated venous pressure of the dog. The arrows represent the intravenous administration of $5.5 \mathrm{mg} . / \mathrm{kg}$. body weight of TEAB.

pressure occurred. Cardiac output increased slightly. After waking the patient venous pressure rapidly returned to starting levels (Fig. 8). In cases where administration of evipan failed to induce sleep no significant changes occurred (Group VII of Table I).

A toxic dose of evipan resulted in a further elevation of right auricular pressure and in a decrease in cardiac output and arterial pressure. The changes in right auricular pressure and cardiac output are opposite to those observed during sleep (Group VIII of Table I).

Sleep has no effect on normal venous pressure.

\section{Discussion}

Besides their sympathicolytic property, ergotamine derivatives possess a vasoconstrictor effect due to their direct action on vascular smooth muscle. Delius et al. (1948) and Hammerschmidt et al. (1950) attributed the rise in venous pressure following their intake to this effect. This view was 


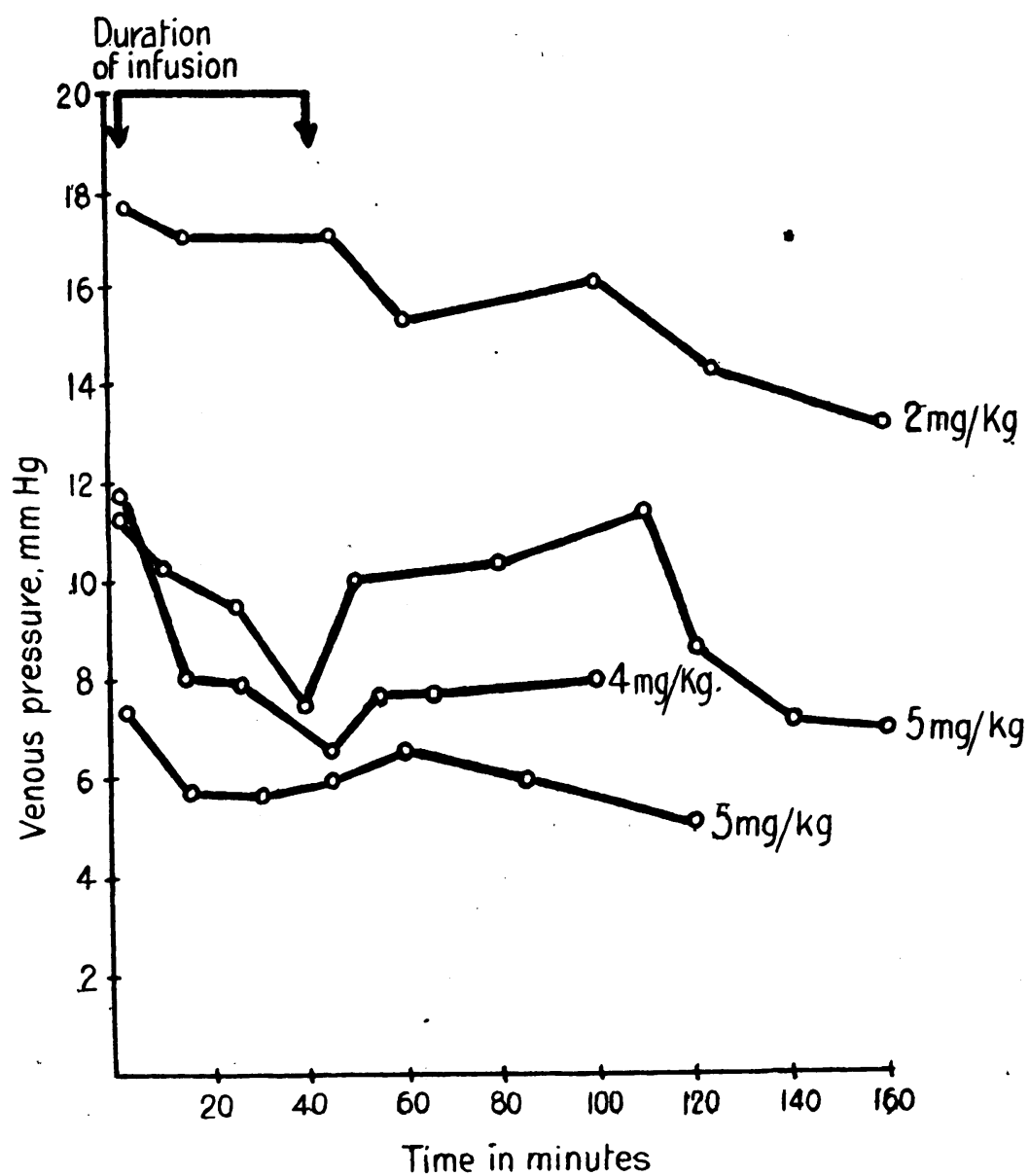

Fig. 7.-The course of the effect of dibenamine on elevated venous pressure in chronic congestive heart failure.

supported by the following observations. Venous hypertension resulting from DHE administration: $(a)$ is brought about without significant changes in arterio-venous oxygen difference or cardiac output, $(b)$ is neither prevented nor discontinued by TEAB (Fig. 4), nor atropine (Fig. 3), (c) is completely reversed by sodium nitrite (Fig. 4), (d) is less marked following hydergin (Group II of Table I), and (e) ensues before the onset of bradycardia (Fig. 1).

Supposing that the effect of DHE in elevating venous pressure is unrelated to its sympatholytic activity and is caused by vasoconstriction, the seat of this vasoconstriction had to be decided. It is unlikely to be located on the arterial side of the circulation. Venous constriction, as a cause of venous hypertension is, however, not unanimously accepted. Landis and Hortenstine (1950) suggest that widespread venous constriction raises central venous pressure only if the heart can not accept the added venous return because it is unable through reduced competence to elevate its output correspondingly. This assumption was not supported: pressure elevation following DHE administration was similar both in normal and in decompensated patients. Fremont-Smith (1949) points out that constriction of the veins increase their resistance and not their pressure. DHE does not influence venous pressure in animals, despite the similarity of action in all other respects. It seems that the effect of venous constriction on venous pressure is different in man and in animals. This assumption may be supported by the fact that venous hypertension of endogenous origin (chronic congestive heart failure) is an extremely rare condition in animals. 


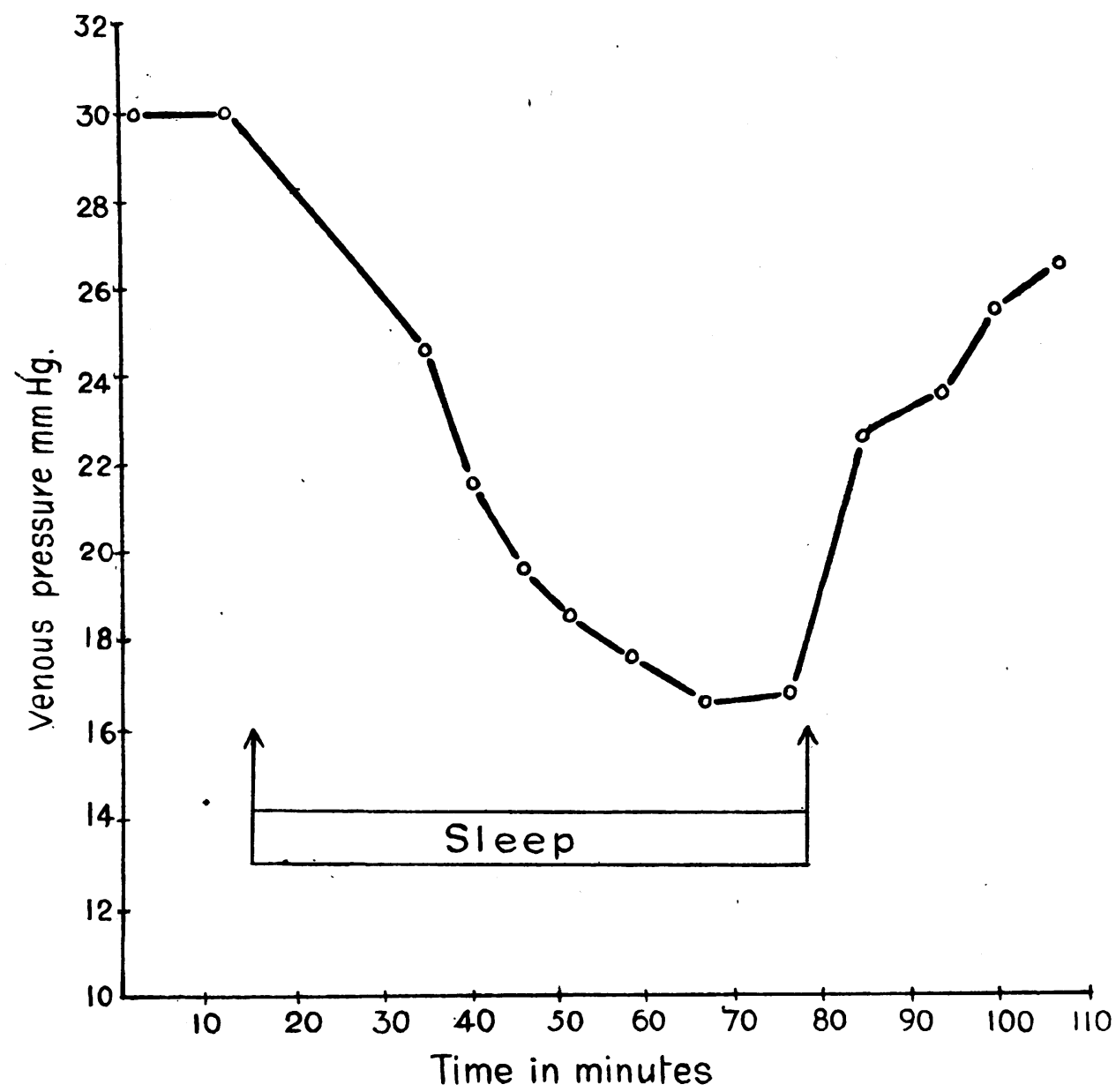

FIG. 8.-The effect of sleep on venous pressure in chronic congestive heart failure.

By accepting the venous pressure raising effect of venous constriction, a new contradiction emerges. In congestive heart failure there is a marked dilatation of the visible veins. Stead (1949) assumes that the dilatation concerns only the large, visible veins, with a simultaneous constriction of the small ones. This view seems to be supported by the effect of sodium nitrite (Group III of Table 1 ), causing venous dilatation as a result of relaxation of smooth muscle. It seems that in the absence of venous constriction sodium nitrite would be unable to reduce venous pressure in congestive heart failure: normal venous pressure remains uninfluenced.

It is characteristic of both substances that they influence venous pressure in a dose insufficient to alter arterial pressure.

The effect of drugs acting on different parts of the nervous system led to the conclusion that this presumable venous constriction is under nervous control.

The decrease of right atrial pressure in heart failure following administration of TEAB (Group IV of Table I) is incident to a simultaneous decrease in arterial pressure and increase in cardiac output. The decrease of right atrial pressure is, however, not a mere consequence of the latter two changes. This seems to be proven by the following observations: right atrial pressure decreased even in those cases where no increase in cardiac output occurred; the venous pressure of dogs subjected to large intravenous infusions, did not decrease following injection of TEAB, despite its similar effect on arterial pressure and cardiac output (Fig. 6). This latter observation seems 
further to indicate that a simple elevation of circulating plasma volume does not create a condition similar to human congestive heart failure: whereas the former is a simple mechanical distension of the venous system, the latter is a true venous hypertension, being - in analogy to benign arterial hypertension-due to an active participation of the nervous system. (The possibility of a nervously mediated independent venous hypertension was at first emphasized by Condorelli, 1947.) A further support of the above statement is found in the effect of dibenamine, and in that of sleep. Dibenamine resulted in a decrease in venous pressure in congestive heart failure (Group $\mathrm{V}$ of Table I.) This decrease, however, was in most cases unrelated to the effect on the arterial pressure, and occurred without any concomitant change in cardiac output. No explanation is offered for the early occurrence (Fig. 7) of this effect.

The analogous mechanism of arterial and venous hypertension is further supported by,observations made during sleep (Group VI of Table I). It has long been known that arterial pressure of hypertensive subjects decreases during sleep, showing the role of the central nervous system in the maintenance of benign arterial hypertension. Venous pressure in congestive heart failure exhibits a similar reversible decrease during sleep (Fig. 8), appearing to be unrelated to a simultaneous change in arterial pressure and cardiąc output.

Frew and Rosenheim (1949) in their paper on the labile neurogenic component of arterial hypertension emphasize the existence of a common neurogenic element ("supplemental pressure," Alam and Smirk, 1943). They proved that TEAB and barbiturate act upon the same neurogenic element of hypertension though at different levels of the reflex arc: the minimum diastolic pressures obtained with TEAB and barbiturates in cases of arterial hypertension were identical. The venous pressure in heart failure behaves in a similar manner. By blocking muscular or neurogenic impulses with sodium nitrite, TEAB, dibenamine, or sleep, the decrease in venous pressure is always the same: about 35 per cent (Table I). It seems that mechanical factors are only responsible for the rest of the venous hypertension. Yet a difference from arterial hypertension exists. While the removal of the neurogenic element may have little effect in advanced stages of arterial hypertension, the neurogenic element of venous hypertension seems to bear no relation to the time of onset or progress of heart failure.

The above experiments fail to throw light on the unknown stimulus causing the nervous excitation which leads to venous hypertension. Anoxia alone does not seem to be responsible for this phenomenon: cyanotic forms of congenital heart disease fail to exhibit elevated venous pressure.

Patients were not especially benefited by the decrease in venous pressure, brought about by the administration of the aforementioned, extracardially acting substances; diuresis was never enhanced. This observation seems to support the view that despite predominance of peripheral signs, the final cause of the complex clinical entity, known as chronic congestive heart failure is, after all, the failing myocardium (Ahmed et al., 1950).

In face of the facts pointing out the important part of the nervous system in maintaining venous hypertension, Pavlov's words may be recalled (1951): “. . . The more the nervous system of an organism is developed, the more its highest section predominates in organizing and arranging all its bodily functions, although this is not always manifest."

A study concerning the role of the nervous system in maintenance of pulmonary hypertension is in progress.

\section{SUMMARY}

In an attempt to investigate the possibility of independent reactions of the venous system, the following facts were established. Ergotamine derivations cause a rise in peripheral and central venous pressure in man, but not in animals. Sodium nitrite decreases the right atrial pressure in heart failure, but not in normal persons. Both drugs exert their action by affecting the smooth muscle of the veins. Contraction or relaxation of the muscle of the venous system seems to result in a rise or decrease in its pressure. Phlebohypertension in heart failure is partly due to a constriction of the small veins. 
Venous constriction in heart failure is mediated by the sympathetic nervous system and controlled by higher brain centres. In analogy with benign arterial hypertension, venous hypertension also possesses a " common neurogenic component" (Frew and Rosenheim, 1949). Venous pressure elevation in dogs subjected to a large intravenous infusions does not decrease following administration of TEAB. The conclusion was reached that expanding blood volume does not create conditions identical with human heart failure.

High venous pressure in heart failure is a combination of two factors: (a) a mechanical factor (high blood volume, back pressure, etc.), and $(b)$ a functional factor (nervously produced venous constriction).

Our thanks are due to Mr. K. Szeitz for his invaluable help and assistance.

\section{REFERENCES}

Ahmed, S., Bayliss, R. I. S., Briscoe, W. A., and McMichael, J. (1950). Clin. Sci., 9, 1.

Alam, N., and Smirk, F. H. (1943). Brit. Heart J., 5, 156.

Bakos, A. C. P. (1950). Circulation, 1, 724.

Condorelli, L. (1947). Fisiopatologia della Circolazione Venosa. Pagnano, Catania.

Cournand, A., and Ranges, H. A. (1941). Proc. Soc. exp. Biol., N.Y., 46, 462.

Delius, L., Hammerschmidt, D., and Odenthal, F. (1948). Festschr. f. Herrn Prof. Rothlin, Schwabe, Basel.

Fisher, R. A. (1934). Statistical Methods for Research Workers. Oliver \& Boyd, London.

Fremont-Smith, F. (1949). Trans. III, Conf. of J. Macy Jr., Found. New York, p. 184.

Frew, J. L., and Rosenheim, M. L. (1949). Clin. Sci., 7, 217.

Gibbons, T. B. (1948). Amer. Heart J., 35, 553.

Gollwitzer-Meyer, K. (1932). Ergebn. Physiol., 34, 1145.

Gowdey, C. W., Loynes, J. S., and Wand, R. A. (1950). Rev. Canad. biol., 9, 74.

Guyton, A. C. (1950). Amer. J. Physiol., 163, 718.

Halmágyi, D., Felkai, B., and Iványi, J. (in press). J. clin. Path.

Hamburger, W. W., and Lev, M. W. (1925). J. Amer. med. Ass., 84, 587.

Hammerschmidt, D., and Odenthal, F. (1950). Ztschr. Kreislauff., 39, 150.

Hayward, G. W. (1948). Lancet, 1, 18.

Huckabee, W., Casten, G., and Harrison, T. R. (1950). Circulation, 1, 343.

Iglauer, A., and Altschule, M. D. (1940). J. clin. Invest., 19, 503.

Issekutz, Jr., B., Hetényi,'Jr., G., and Feuer, I. (1949). J. Physiol., 108, 32.

Landis, E. M., Brown, E., Fauteaux, M., and Wise, C. (1946). J. clin. Invest., $25,237$.

and Hortenstine, J. C. (1950). Physiol. Rev., 30, 1.

McDowall, R. J. S. (1935). Physiol. Rev., 15, 99.

McMichael, J. (1948). Brit. med. J., 2, 927.

Nickerson, M., and Goodman, L. S. (1948). Federation Proc., 7, 397.

Pavlov, I. (1951). Selected Works, Hungarian Academy of Sci., Budapest (in Hungarian).

Rappaport, M., and Sarnoff, S. J. (1949). Federation Proc., 8, 130.

Relman, A. S., and Epstein, F. H. (1949). Proc. Soc. exp. Biol., N.Y., 70, 11.

Rodbard, S., and Wagner, D. (1949). Proc. Soc. exp. Biol., 71, 69.

Ross, J. F., Baker, W. H., and Freis, E. D. (1950). J. clin. Invest., $29,842$.

Scaffidi, L., and D'Agostino, L. (1940). Cardiologia, 4, 107.

Shorr, E., Zweifach, W. B., Furchtgott, R. F., and Baez, S. (1951). Circulation, 3, 42.

Shuman, C. R. (1950). Amer. Pract., 1, 904.

Starr, I., Jeffers, M., and Meade, A. (1943). Amer. Heart J., 26, 291.

Stead, Jr., E. (1949). Trans. III, Conf. of J. Macy, Jr., Found. New York, p. 182.

Turner, R. (1950). Lancet, $2,353$.

Warren, M., and Stead, Jr., E. (1944). Arch. intern. Med., 73, 138.

Weiss, S., Willkins, R. W., and Haynes, F. W. (1937). J. clin. Invest., 16, 73.

Willkins, R. W., Haynes, F. W., and Weiss, S. (1937). J. clin. Invest., 16, 85.

,--1 (1938). J. clin. Invest., 17, 41.

Yeomans, A., Porter, R. R., and Swank, R. L. (1943). J. clin. Invest., 22, 33. 